\title{
POLA ASUH ORANGTUA AKAN MENINGKATKAN ADAPTASI \\ SOSIAL ANAK PRASEKOLAH DI RA MUSLIMAT NU 202 ASSA'ADAH SUKOWATI BUNGAH GRESIK
}

\author{
Suana $^{*}$, Firdaus ${ }^{* *}$ \\ UNUSA, Fakultas Keperawatan dan Kebidanan - Jl. SMEA 57 Surabaya \\ E-mail: firdausbakdil@yahoo.co.id
}

\begin{abstract}
Each child has a different ability to adapt. Some children experience the late process of social adaptation during preschool age. Therefore, this research was purposed to find out the correlation between parenting pattern and social adaptation development in preschool children studying at RA Muslimat NU 202 Assa'adah Sukowati, Bungah, Gresik. The type of research was analytic done by applying cohort retrospective design. The population involved all parents and their children studying at the school mentioned above, totally 40 people, in which 36 respondents were taken as the samples by using probability sampling, namely simple random sampling technique. Questionnaires and observational sheets were used to collect the data, which were then analyzed by using Spearman's Rank correlation test with the significance level of 0.05. The result of research showed that most of the respondents (55.6\%) applied democrative, whereas nearly all of the children (80\%) had a good social adaptation development. Moreover, the result of correlation test showed that $p=$ $(0.000)<\alpha(0.05)$ so that $H_{0}$ was rejected illustrating that there was a correlation between parenting pattern and social adaptation development in preschool children studying at RA Muslimat NU 202 Assa'adah Sukowati, Bungah, Gresik. The research concluded that the parents applying democratic parenting pattern resulted in a good social adaptation development in their children. Thus, they should apply the correct parenting pattern according to the age of their children.
\end{abstract}

\begin{abstract}
ABSTRAK: Kemampuan setiap anak dalam beradaptasi berbeda-beda. Beberapa anak mengalami keterlambatan dalam proses adaptasi sosial di masa prasekolah. Tujuan penelitian untuk mengetahui hubungan pola asuh orangtua dengan perkembangan adaptasi sosial anak prasekolah di RA Muslimat NU 202 Assa'adah Sukowati Bungah Gresik. Desain penelitian menggunakan metode analitik dengan desain penelitian kohort retrospektif. Populasi ini seluruh orangtua beserta anak di RA Muslimat NU 202 Assa'adah Sukowati Bungah Gresik sebesar 40 responden. Sampel diambil menggunakan probability sampling, teknik simple random sampling. Besar sampel 36 responden. Data diperoleh melalui kuesioner dan lembar observasi dan dianalisis menggunakan uji korelasi Rank Spearman dengan tingkat signifikan $\alpha=0,05$. Hasil penelitian menunjukkan bahwa sebagian besar $(55,6 \%)$ responden menerapkan pola asuh demokratis, hampir seluruh $(80 \%)$ responden memiliki perkembangan adaptasi sosial baik. Hasil uji korelasi Rank Spearman didapatkan nilai $\rho(0,000)<\alpha=0,05$ maka $\mathrm{H}_{0}$ ditolak berarti ada hubungan Pola Asuh Orangtua dengan Perkembangan Adaptasi Sosial Anak Prasekolah di RA Muslimat NU 202 Assa'adah Sukowati Bungah Gresik. Simpulan dari penelitian adalah orangtua yang menerapkan pola asuh demokratis, menghasilkan perkembangan adaptasi sosial anak baik. Orangtua disarankan menerapan pola asuh yang tepat dan sesuai dengan usia anak.
\end{abstract}

Kata Kunci : Orang tua, perkembangan, adaptasi sosial 


\section{PENDAHULUAN}

Masa prasekolah atau periode 5 tahun pertama kehidupan anak sering disebut juga sebagai golden periode, window opportunity, atau critical periode. Periode ini merupakan masa pertumbuhan dan perkembangan yang paling pesat pada otak manusia, kebutuhan tumbuh kembang merupakan salah satu hak dasar anak sesuai Undangundang Nomor 23 tahun 2003 tentang Perlindungan Anak dan Konvensi Hakhak Anak tahun 1989/1990 (Wijaya, 2009).

Ketika memasuki usia prasekolah, kemampuan anak untuk beradaptasi sudah dapat dimanfaatkan dengan baik. Namun pada kenyataannya banyak ditemukan keterlambatan penyesuaian sosial (adaptasi) terutama diusia awal sekolah. Masalah tersebut diantaranya kemampuan yang kurang dalam proses sosialisasi di lingkungan. Dalam hal ini anak belum mampu bersosialisasi dengan baik dalam hal berinteraksi dengan teman sebaya, sehingga anak dalam prosesnya mengalami kendala kesiapan yang ditunjukkan dengan perilaku menyimpang seperti takut ditinggal ibunya, bermain sendiri, anak yang terlalu impulsif atau hiperaktif (Hurlock, 2010). Banyak orangtua yang tidak menyadari bahwa pola asuh yang diterapkan kepada anak setiap harinya dapat berpengaruh terhadap perkembangan adaptasi sosial anak. Orangtua cenderung membiarkan anak dikarenakan faktor kesibukan, seperti kedua orangtuanya yang bekerja. Namun, masih banyak pula orangtua yang tidak mampu berinteraksi dengan anaknya karena ketidaksiapan menjadi orangtua, beberapa orangtua juga hanya menyibukkan dirinya dengan pekerjaan rumah (Soetjiningsih, 2012).

Berdasarkan hasil observasi pada tanggal 14 Januari 2014 yang dilakukan peneliti di RA Muslimat NU 202 Assa'adah Sukowati Bungah Gresik didapatkan data secara acak dari 7 anak, terdapat 3 anak mampu beradaptasi secara baik terhadap teman dan lingkungannya, sedangkan terdapat 2 anak bersifat agresif dan suka mengambil mainan temannya, 2 anak lainnya lebih suka menyendiri dan penakut, tidak mau ditinggal orangtuanya pada saat proses pembelajaran dimulai dan berdasarkan wawancara pada orangtua, didapatkan data 2 orangtua mengatakan membiarkan anaknya berprilaku sesuai keinginan anak tanpa ada batasan, 2 orangtua lainnya, mengatakan sering memberikan hukuman ringan pada anak seperti menjewer ketika anak melakukan kesalahan.

Apabila sejak masa awal ini anak tidak mampu melakukan hubungan sosial dengan baik, maka dimasa remajanya anak akan merasa tidak percaya diri dan tidak mampu bersosialisasi secara aktif di masyarakat. Anak akan sering menyendiri dan melamun yang dalam lamunan itu mereka berperan sebagai orang yang teraniaya. Anak secara sengaja menolak berkomunikasi dengan orang lain kecuali bila perlu sehingga anak akan sulit diterima anggota kelompok sosial di lingkungannya (Hurlock, 2010).

Upaya yang dapat dilakukan oleh tenaga kesehatan untuk meningkatkan pemahaman orangtua tentang pola asuh terhadap anak adalah memberikan penyuluhan dan pendekatan kepada orangtua. Orangtua diberikan penjelasan tentang pola asuh yang tepat diberikan kepada anak prasekolah agar tidak keliru memberikan pengasuhan yang akan berdampak pada perkembangan adaptasi sosial anak. Keberhasilan perkembangan adaptasi sosial anak dapat dicapai dari sikap orangtua dalam mengasuh anak sejak dini. Orangtua harus mampu memahami kebutuhan anak, yang berguna untuk menjamin perlindungan anak yang optimal terhadap lingkungan. Orangtua juga harus aktif dalam memberikan bimbingan, pendidikan dan rasa kasih sayang yang akan 
mempengaruhi perkembangan mental dan sosial anak.

\section{METODE PENELITIAN}

Jenis penelitian yang digunakan adalah analitik dengan desain penelitian kohort Retrospektif. Populasi dalam penelitian ini adalah seluruh orangtua beserta anak di RA Muslimat NU 202 Assa'adah Sukowati Bungah Gresik sebesar 40 orangtua dan 40 anak. Instrumen penelitian menggunakan kuesioner dan lembar observasi. Jadi besar sampel dalam penelitian ini adalah sebagian orangtua dan sebagian anak di RA Muslimat NU 202 Assa'adah Sukowati Bungah Gresik sebesar 36 orangtua dan 36 anak. Pengambilan sampel dilakukan secara probability sampling dengan teknik simple random sampling.

\section{HASIL}

Hasil Data khusus berisi karakteristik responden yang meliputi frekuensi pola asuh orangtua, adaptasi sosial anak, dan hubungan pola asuh orangtua dengan perkembangan adptasi sosial anak.

a. Karakteristik responden berdasarkan pola asuh orangtua

Tabel 5.5 Distribusi frekuensi responden berdasarkan pola asuh orangtua di RA Muslimat NU 202 Assa'adah Sukowati Bungah Gresik

\begin{tabular}{ccc}
\hline $\begin{array}{c}\text { Pola Asuh } \\
\text { Orangtu } \\
\text { a }\end{array}$ & Frekuensi & $\begin{array}{c}\text { Persentase } \\
(\%)\end{array}$ \\
\hline Demokratis & 20 & 55,6 \\
Permisif & 9 & 25 \\
Otoriter & 7 & 19,4 \\
\hline Jumlah & 36 & 100 \\
\hline
\end{tabular}

Data primer : Maret 2014

Tabel 5.5 menunjukkan bahwa dari keseluruhan 36 responden sebagian besar $(55,6 \%)$ responden menerapkan pola asuh demokratis.

b. Karakteristik responden berdasarkan perkembangan adaptasi sosial anak
Tabel 5.6 Distribusi frekuensi responden berdasarkan perkembangan adaptasi sosial anak di RA Muslimat NU 202 Assa'dah Sukowati Bungah Gresik

\begin{tabular}{ccc}
\hline $\begin{array}{c}\text { Adaptasi } \\
\text { sosial }\end{array}$ & Frekuensi & $\begin{array}{c}\text { Persentase } \\
\%)\end{array}$ \\
\hline Baik & 19 & 52,8 \\
Cukup & 10 & 27,8 \\
Kurang & 7 & 19,4 \\
\hline Jumlah & 36 & 100 \\
\hline
\end{tabular}

Data primer : Maret 2014

Tabel 5.6 menunjukkan bahwa dari keseluruhan 36 responden sebagian besar $(52,8 \%)$ responden memiliki perkembangan adaptasi sosial baik.

c. Tabulasi silang pola asuh orangtua dengan perkembangan adaptasi sosial anak prasekolah.

Tabel 5.7 Tabulasi silang pola asuh orangtua dengan perkembangan adaptasi sosial anak prasekolah di RA Muslimat NU 202 Assa'dah Sukowati Bungah Gresik

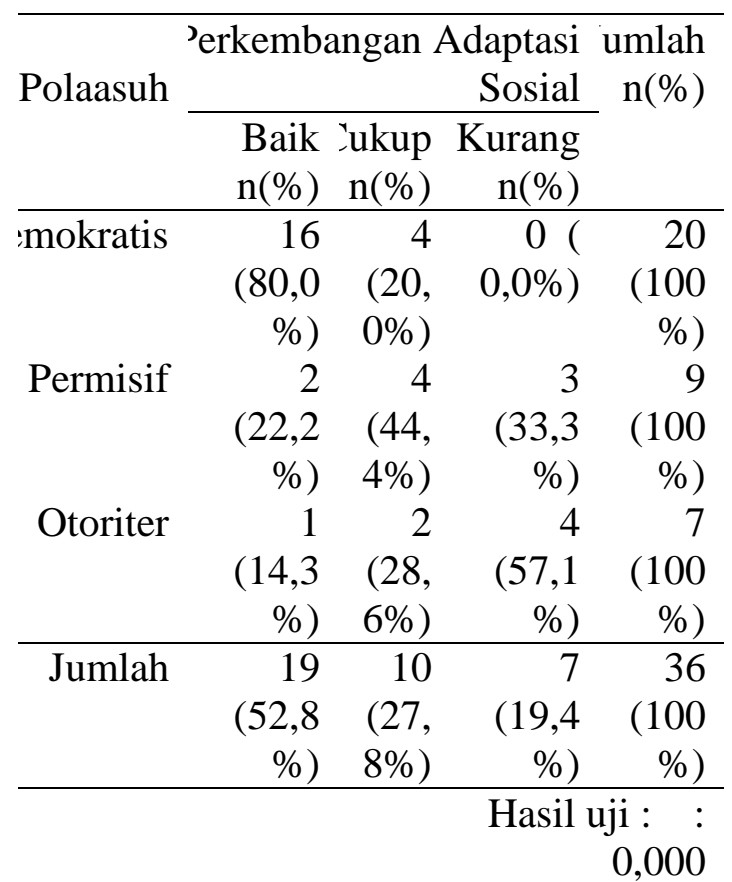

Data primer : Maret 2014

Tabel 5.7 menunjukkan bahwa dari keseluruhan 36 responden 20 responden dengan pola asuh demokratis hampir seluruh (80\%) memiliki perkembangan adaptasi sosial baik, 9 
responden dengan pola asuh permisif hampir setengah $(44,4 \%)$ memiliki perkembangan adaptasi sosial cukup sedangkan 7 responden dengan pola asuh otoriter sebagian besar $(57,1 \%)$ memiliki perkembangan adaptasi sosial kurang. Berdasarkan uji korelasi Rank Spearman didapatkan $\rho=0,000<\alpha=0,05$ yang artinya $\mathrm{H}_{0}$ ditolak, berarti ada hubungan pola asuh orangtua dengan perkembangan adaptasi sosial anak prasekolah di RA Muslimat NU 202 Assa'adah Sukowati Bungah Gresik.

\section{PEMBAHASAN}

Pola asuh adalah suatu keseluruhan interaksi antara orangtua dengan anak, dimana orangtua bermaksud menstimulasi anak dengan mengubah tingkah laku, pengetahuan serta nilai-nilai yang dianggap paling tepat oleh orangtua, agar anak dapat mandiri, tumbuh dan berkembang secara optimal dan dapat diterima oleh masyarakat (Pieter, 2010).

Faktor pertama yang mempengaruhi pola asuh orangtua adalah Pendidikan orangtua. Pendidikan orangtua dalam perawatan anak akan mempengaruhi persiapan mereka menjalankan pengasuhan. Ada beberapa cara yang dapat dilakukan untuk menjadi lebih siap dalam menjalankan peran pengasuhan antara lain : terlibat aktif dalam setiap pendidikan anak, selalu berupaya menyediakan waktu untuk anak-anak dan menilai perkembangan fungsi keluarga dan kepercayaan anak.

Faktor kedua yang mempengaruhi pola asuh orangtua adalah Pengalaman orangtua. Orangtua yang sudah mempunyai pengalaman sebelumnya dalam mengasuh anak akan lebih siap menjalankan peran asuh, selain itu orangtua akan lebih mampu mengamati tanda-tanda pertumbuhan dan perkembangan yang normal.

Faktor ketiga yang mempengaruhi pola asuh orangtua adalah Lingkungan . Lingkungan banyak mempengaruhi perkembangan anak, maka tidak mustahil jika lingkungan juga ikut serta mewarnai pola-pola pengasuhan yang diberikan orangtua terhadap anaknya.

Faktor keempat yang mempengaruhi pola asuh orangtua adalah Budaya. Sering kali orangtua mengikuti cara-cara yang dilakukan oleh masyarakat dalam mengasuh anak, kebiasaan-kebiasaan masyarakat sekitarnya dalam mengasuh anak karena pola-pola tersebut dianggap berhasil dalam mendidik anak kearah kematangan. Orangtua mengharapkan kelak anaknya dapat diterima dimasyarakat dengan baik, oleh karena itu kebudayaan atau kebiasaan masyarakat dalam mengasuh anak juga mempengaruhi setiap orangtua dalam memberikan pola asuh terhadap anaknya. Menurut Desmita (2009) faktor-faktor yang mempengaruhi adaptasi sosial (penyesuaian diri) dilihat dari konsep psikogenik dan sosiopsikogenik. Psikogenik memandang bahwa adaptasi sosial dipengaruhi oleh riwayat kehidupan sosial individu, terutama pengalaman khusus yang membentuk perkembangan psikologis. Pengalaman khusus ini lebih banyak berkaitan dengan latar belakang kehidupan keluarga, terutama menyangkut aspek-aspek :

1.Pola asuh orangtua, yang merujuk pada iklim hubungan sosial dalam keluarga, apakah hubungan tersebut bersifat demokratis, permisif atau otoriter

2.Iklim intelektual keluarga, yang merujuk pada sejauh mana iklim keluarga memberikan kemudahan bagi perkembangan intelektual anak, pengembangan berpikir logis atau irrasional.

3.Iklim emosional keluarga, yang merujuk pada sejauh mana stabilitas hubungan dan komunikasi di dalam keluarga terjadi.

Sementara itu dilihat dari konsep sosiopsikogenik, adaptasi sosial dipengaruhi oleh faktor iklim lembaga 
sosial dimana individu terlibat didalamnya. Bagi siswa, faktor sosiopsikogenik yang dominan mempengaruhi adaptasi sosial adalah sekolah, yang mencakup :

1) Hubungan guru-siswa, yang merujuk pada iklim hubungan sosial dalam sekolah, apakah hubungan tersebut bersifat demokratis, permisif atau otoriter.

2) Iklim intelektual sekolah, yang merujuk pada sejauh mana perlakuan guru terhadap siswa dalam memberikan kemudahan bagi perkembangan intelektual siswa sehingga tumbuh perasaan kompeten

Dari hasil penelitian banyak orangtua menerapkan pola asuh demokratis sehingga memiliki anak dengan perkembangan adaptasi sosial baik. Anak dengan pola asuh demokratis ini akan diberikan kebebasan oleh orangtuanya untuk mengemukakan pendapat, perasaan dan keinginannya. Jadi dalam pola asuh ini terdapat komunikasi yang baik antara orangtua dan anak.

\section{SIMPULAN}

Simpulan yang didapatkan dari hasil penelitian dan pembahasan mengenai hubungan pola asuh orangtua dengan perkembangan adaptasi sosial anak prasekolah di RA Muslimat NU 202 Assa'adah Sukowati Bungah Gresik, sebagai berikut :

1. Responden orangtua di RA Muslimat NU 202 Assa'adah Sukowati Bungah Gresik sebagian besar menerapkan pola asuh demokratis.

2. Responden anak prasekolah di RA Muslimat NU 202 Assa'adah Sukowati Bungah Gresik sebagian besar memiliki perkembangan adaptasi sosial baik.

3. Ada hubungan pola Asuh asuh orangtua dengan perkembangan adaptasi sosial anak prasekolah di RA Muslimat NU 202 Assa'adah Sukowati Bungah Gresik.

\section{DAFTAR PUSTAKA}

Ayuningsih, Diah. (2011). Psikologi Perkembangan Anak. Yogyakarta, Pustaka Larasati

Bahiyatun. (2010). Buku Ajar Bidan Psikologi Ibu \& Anak. Jakarta, EGC

Dahlan, M. Djawad. (2004). Psikologi Perkembangan Anak dan Remaja. Bandung, PT. Remaja Rosdakarya

Desmita (2009). Psikologi Perkembangan. Bandung, Rosda

Driyas, Anung. (2012). Pola Asuh Orangtua Dalam Mendidik Anak Usia Dini. http://anungdriyas.wordpress.com/kar ya-ilmiah/pendidikan-anak-usiadini/pola-asuh-orang-tua-dalammendidik-anak-usia-dini/. Artikel diakses tanggal 14 Januari 2014

Fadhi, Nurul. (2012). Faktor-Faktor Yang Mempengaruhi Pola Asuh. jtptunimus-gdl-nurulfadhi-5489-4babii.pdf. Artikel diakses tanggal 15 Januari 2014

Hidayat, A. Aziz (2008). Pengantar Ilmu Kesehatan Anak untuk Pendidikan Kebidanan. Jakarta : Salemba Medika Hurlock, Elizabeth (2010). Perkembangan Anak Jilid 1 Edisi Keenam. Jakarta : Erlangga

Indrawati

(2008).http://elibrary.ub.ac.id/bitstrea $\mathrm{m} / 123456789 / 18026 / 1 /$ Perbedaantingkat-perkembangan-anak-usia-2-3-Tahun-yang-tidak-mengikutiaktivitas--bermain-dan-yangmengikuti-aktivitas-bermain-PlayGroup-di-Kelurahan-Sidoharjo-

Kecamatan-Lamongan..pdf. Diakses tanggal 2 mei 2014

Iswantini, H. (2002). Hubungan Antara Pola Asuh Otoriter dengan Locus Of Control. Skripsi. Surakarta Fakultas Psikologi Universitas Muhammadiyah, Tidak dipublikasikan

Nugroho, Wahyudin. (2008). Keperawatan Gerontik dan Geniatrik. Jakarta : EGC 
Nursalam. (2008). Asuhan Keperawatan Bayi dan Anak (untuk perawat dan bidan). Jakarta : Salemba Medika

Nursalam. (2008). Konsep dan Penerapan Metodologi Penelitian Ilmu Keperawatan Pedoman Skripsi, Tesis dan Instrumen Penelitian Keperawatan. Jakarta, Salemba Medika.

Nuryati,Lusi. (2008). Psikologi anak. Jakarta : Indeks

Notoatmodjo, S. (2010). Metodologi Penelitian Keperawatan. Jakarta : Renika Cipta
Pieter, Zan Herri., Namora Lumangga Lubis. (2010). Pengantar Psikologi dalam Keperawatan. Jakarta, Kencana

Sulistiyawati (2011). http://artikelduniawanita.com/sudahbenarkah-pola-asuh-anak-kita.html . Diakses tanggal 23 April 2014

Soetjiningsih, Christiana Hari. (2012). Perkembangan Anak Sejak Pembuahan Sampai dengan Kanakkanan Akhir. Jakarta : Prenada Yogyakarta, Ar Ruzz Media. 